


\section{Hacia la propuesta de un tiempo poético en la narrativa ficcional: el presente eterno en la configuración del nunc fluens}

Gabriela Trejo Valencia Universidad de Guanajuato

Resumen:

La idea general del artículo es elucidar una configuración temporal opuesta a la cronología tradicional, para ello enfatizaremos que una de las alternativas más importantes para salir de la convención lineal del tiempo es pensarlo como una estructura profunda muy independiente de la falsa flecha del acontecer. Proponemos una lectura que revalore la temporalidad ficcional, para lo cual, revisaremos cómo la narrativa puede representar un tiempo no susceptible de explicación lógica. Por último, el análisis se centrará en la noción de nunc fluens, configuración de un presente eterno que en determinadas narrativas develará un tiempo poético empíricamente imposible pero ficcionalmente viable.

Palabras clave: tiempo ficcional, temporalidad poética, narrativa, nunc fluens, presente eterno.

\section{Abstract:}

The general idea of the article is elucidate a temporary configuration opposite to the traditional chronology, to do so the text emphasizes that one of the most important alternatives to come out of the convention about lineal time is thinking about him as a deep structure quite independent of the fake arrow of time. We propose a reading that revaluates the fictional temporality, thus, 
we will review how the narrative can represents a poetic temporality without logical explanation. Finally, the analysis will focus on the notion of nunc fluens, the configuration about an eternal present that in certain narratives will unveil a temporality poetic empirically impossible but fictionally viable.

Key words: Fictional time, Temporality poetic, Narrative, Nunc fluens, Eternal present.

El tiempo ni pasa ni vuela, no obstante las expresiones que las personas inmersas en su quehacer emplean a menudo en lugares comunes... tampoco marcha el tiempo en una dirección, puesto que per se, ni avanza ni apunta hacia parte alguna

Elliot JaQues

\section{Tiempo y narración}

G l tiempo es quizá el hito más regular del devenir de los hombres, no en vano la sensación de su paso es capital para nuestra consciencia del ser en el mundo. El flujo de asociaciones lineales (pasado-presente-futuro) que hacemos alrededor del tiempo, más que una estrategia para intentar aprehenderlo, es la forma inequívoca usada como principio de construcción de la propia existencia; inclusive, debido a ello, ésta se pondera sociológicamente en relación a la cuantificación de los periodos en el suceder del calendario. Esta perspectiva metódica, que al racionalizar el tiempo lo dota de la capacidad de organizar sistemáticamente el quehacer humano a través del relato más o menos ordenado de nuestros actos, encuentra eco en el enfoque mecanicista del mundo que privilegia la experiencia del tiempo en cuanto a su posibilidad de narrar la vida; de ahí se desprende la innegable interdependencia 
del tiempo respecto a la narración: no entenderíamos uno sin el otro y viceversa.

A todo esto, resulta paradójico invertir esfuerzos en concebir el tiempo como una magnitud cuantificable y, por tanto, divisible, cuando en sentido estricto es una subjetividad incapaz de permanecer en puntual equilibrio lógico, dado que el pasado es inasible; el presente es un instante que si se reconoce, se considera ya como pasado; mientras el futuro es apenas un potencial. ${ }^{1}$ Ante el enigma del tiempo en su conjunto, el propio Agustín de Hipona -figura icónica en cuanto a la disquisición temporal se refiere- reculó en su empeño de considerar al tiempo en su condición de absoluto mesurable y advirtió que a pesar de saber bien qué es el tiempo, a todas luces resulta ser inexplicable.

Frenados en la tentativa de resolver esta problemática, históricamente se orienta la reflexión en la percepción temporal mientras se profundiza en cómo la síntesis del tiempo ${ }^{2}$ (la suposición de vivir el presente, por naturaleza resbaladizo, y relacionarlo con un momento anterior y posterior, éste último también incognoscible) afecta la narrativa del acontecer. Dicho de otro modo, para percibir el tiempo es indispensable sumar y unir los puntos de una supuesta línea temporal; pero si, como considera Kant, el tiempo no tiene constancia sino a partir de la percepción $\mathrm{n}^{3}$ y toda percepción

${ }^{1}$ Una perspectiva similar es enunciada por Boecio en La consolación de la filosofía, ahí puntualiza lo efímero de las etapas temporales cuando dice: "[el hombre] no ha alcanzado todavía el día de mañana, cuando ya ha perdido el día de ayer" (1999: 182).

2 "Esta capacidad de síntesis es lo que caracteriza la forma en que los seres humanos conocen y se orientan en el mundo" (Elias, 2010: 11).

3 "El tiempo únicamente posee validez objetiva en relación con los fenómenos, por ser estos cosas que nosotros consideramos como objetos de nuestros sentidos. [...] En consecuencia, el tiempo no es más que una condición subjetiva de nuestra humana intuición [...] y en sí mismo, fuera del sujeto, no es nada” (Kant, 1988: 76-78). 
se da en el tiempo, entonces parecería una aporía pretender fundar la conciencia del conocimiento Histórico.

Debido a que el tiempo es este poderoso material simbólico por medio del cual forjamos la narrativa de la realidad, allende la filosofía pocos ámbitos de conocimiento se han abstenido de reflexionar tangencial o decididamente acerca de su condición de Absoluto, su carácter de magnitud direccional o su concepción ahistórica. La disquisición que suele eludir este posicionamiento encuentra justamente en el campo filosófico y estético un asidero que posibilita repensar la fluencia ordinaria, ante todo al enfocarse en determinadas expresiones narrativas que desde el artificio de la obra y aun sin cumplir con la certeza del tiempo Histórico, ${ }^{4}$ despliegan una auténtica trama.

Ahora bien, si se distingue entre narrativa cronológica y narrativa desde el punto de vista ficcional es porque para la primera cada uno de los puntos de la flecha temporal es medible, mientras para la segunda existe un tiempo no susceptible de explicación lógica ni sintética, esto porque involucra una suerte de relatividad capaz de cuestionar la enseńanza Heraclitana acerca de que todo pasa y todo fluye. ${ }^{5}$ A partir de estas diferencias deriva la dificultad de cavilar

${ }^{4}$ El Historicismo será entendido desde el paradigma filosófico alemán de la primera parte del siglo XIX, el cual apunta hacia un tiempo histórico y a la ciencia que lo estudia:"historicismo, en el uso científico de la palabra, es la afirmación de que la vida y la realidad son Historia y nada más que Historia"(Croce, 2005: 71). Este modelo de pensamiento facilita referir el tiempo como una magnitud física que permite ordenar la secuencia de los sucesos. A partir de este momento, al enunciar Historia y sus derivados con mayúsculas, referiremosa esta manera de entender el tiempo. Para ahondar en la comprensión de las ciencias y el ser históricos, véase el trabajo de Wilhelm Dilthey en "Esbozos para una crítica de la razón histórica”.

${ }^{5}$ El filósofo presocrático representa este dinamismo en uno de sus aforismos más célebres, "no es posible entrar dos veces en el mismo río" (Heráclito apud en Mondolfo, 2004: 199); en él nos recuerda que por paradójico que sea, lo único permanente es el cambio constante. 
sobre un "tiempo que no corre" sin aludir a su configuración desde el artificio narrativo, ámbito idóneo para mostrar los juegos de la ficción con el tiempo.

El caso del pensamiento griego clásico es ejemplar en este aspecto, basta pensar en las digresiones teórico-filosóficas que dan cuenta de distintas temporalidades no lineales, las cuales, a posteriori serían retomadas por discursos narrativos ficcionales (casi siempre mítico-religiosos o literarios) para acentuar su exención de la cronología. Verbigracia, es factible rastrear una configuración de tiempo mítico en el Timeo de Platón:

Éstas son todas partes del tiempo y el «era» y el «será» son formas devenidas del tiempo que de manera incorrecta aplicamos irreflexivamente al ser eterno. Pues decimos que era, es y será, pero según el razonamiento verdadero sólo le corresponde el «es», y el «era» y el «será» conviene que sean predicados de la generación que procede en el tiempo (1982: 37).

Además de este trazado platónico del tiempo como eternidad, Aristóteles en su libro IV de Física, admite una fenomenología del transcurso temporal que privilegia la idea de que la percepción del tiempo depende del movimiento físico o del cambio en la consciencia del ser (que no es más que otra clase de movimiento). Pero para captar el dinamismo objetivo (fáctico) o subjetivo (espiritual) es menester un alma que lo capte y a partir de él distinga una sucesión temporal que lo guíe por la idea de que nos movemos de un pasado remoto hacia un futuro incierto. Si sólo el cambio implica temporalidad y en el "ahora" no ocurren cambios, entonces el tiempo es un compuesto de partes que ya han sido y otras partes que serán pero ninguna es o está presente, "una parte es la medida del todo, el todo tiene que estar compuesto de partes, pero no parece que el tiempo esté compuesto de ahoras" (Aristóteles, 1998: 152). Para que el sujeto con alma aprecie el movimiento, el ahora 
debería implicar una extensión en donde lógicamente habría punto inicial y final, lo cual es imposible pues el ahora sería entonces también pasado y futuro.

Como puede anticiparse, el Estagirita propone toda una configuración temporal que desborda los fines panorámicos que por ahora nos ocupan; no obstante, conviene resaltar su trabajo cómo un punto axial en el largo camino de una fenomenología de la conciencia temporal, la cual está modulada en el pensamiento clásico gracias también a conceptos como Aión, Cronos o Kairós, términos especialmente pertinentes para asentar la atemporalidad lógica.

Aión es un concepto funcional para referir el tiempo de la vida, es decir, "el tiempo considerado según el lapso o la prolongación de la existencia; tiempo que para ser requiere de un sujeto viviente «tiempo ligado a la persistencia de la fuerza vital que hace ser al individuo"” (Acosta, 2007: 22; cursivas mías); el significado de aliento vital del aión fue modificando su esencia y por un mecanismo de extensión semántica terminó connotando "el tiempo como vida siempre viva, sin principio ni fin” (Campillo, 1991: 37), esto es, sin posibilidad de ser pensado de manera rectilínea.

Pese a la pluralidad de significados de aión, la designación más conocida para referir el tiempo es Cronos. Esta referencia se da en el caso de pensar el tiempo en todo su conjunto, en una generalidad independiente del individuo viviente y por ende, finito; Cronos trasciende al hombre porque se trata de un tiempo fuera del tiempo Histórico medido por el sujeto. ${ }^{6}$ Con todo, existe al menos otra importante conceptualización filosófica griega cargada semánticamente de referencias no direccionales, nos referimos con ello a Kairós o tiempo de sazón, es decir, "el tiempo huma-

${ }^{6}$ Desde una perspectiva del todo distinta, la de la ciencia, recordemos que la concepción Newtoniana señala una lectura similar al entender el tiempo como absoluto que existe y está en fluencia continua independientemente de la percepción humana. 
no y vivo de las intenciones y fines" (Jaques, 1984: 38). En esta noción la percepción subjetiva del tiempo prima en relación a la sucesión real, de ahí que también se le conozca como el tiempo del acontecimiento -aquí y ahora-. A la luz de tales afirmaciones, puede aseverarse que Kairós resulta ideal para potenciar una clase de temporalidad no ordinaria en expresiones narrativas de índole ficcional, sean éstas literarias (como cuentos, novelas, dramaturgia), o mítico-religiosas.

Ahora bien, a pesar de las licencias implícitas en la construcción ficcional, la manifestación narrativa no está exenta del patriarcado temporal, ya que ésta tiene los mismos puntos de referencia (presente, pasado, futuro) aunque se trata de una reconfiguración en donde diversas estrategias permiten relativizar al tiempo, ralentizarlo o incluso suspenderlo.

Una vez puntualizado esto, es preciso reiterar que a pesar de la amplitud conceptual del tiempo no nos enfocamos en todas sus vías, las cuales como puede notarse, terminan excluyéndose y superponiéndose recíprocamente; más bien se retoma Aión, Cronos y Kairós como antecedentes para cimentar la recurrencia de trastocar el sentido de las medidas del tiempo, sólo entonces puede apuntarse a una representación temporal que mediada por la ficcionalidad reafirme la atemporalidad.

El objetivo es dilucidar una configuración temporal que nos recuerde que "Hubo un tiempo en que el tiempo no era sucesión y tránsito, sino manar continuo de un presente fijo, en el que estaban contenidos todos los tiempos, el pasado y el futuro" (Paz, 1999: 226). Conoceremos a esta configuración temporal como nunc fluens, concepto imposible desde el punto de vista empírico pero viable ficcionalmente debido a que suspende el ahora de manera sempiterna. Denominamos al nunc fluens como configuración temporal porque se trata de una representación ficcional del tiempo que tiene una determinada forma (se centra en el presente) y 
propiedades anejas (el presente es interminable) que lo distinguen del tiempo cronológico y de otras configuraciones temporales.

De ese singular carácter se deriva la justificación principal del texto, proponer una manera de pensar o concebir el tiempo que posibilite una renovada categoría de interpretación con una notable riqueza poético-estética, pues el nunc fluens reúne dos elementos irreconciliables en el tiempo ordinario: un presente que se mantiene y un devenir inacabado.

Para efectos prácticos, este artículo se divide en tres apartados. El primero trata de manera sucinta acerca de las manifestaciones atemporales implícitas en las narraciones de tipo ficcional. El segundo articula la configuración de un presente eterno a partir de las condiciones y la producción de sentido propia del nunc fluens. El último apartado consiste en cavilar acerca de las posibilidades y limitaciones del nunc fluens como experiencia temporal reconfigurada en discursos narrativos ficcionales.

Diversas manifestaciones atemporales implícitas en la narrativa de ficción: del tiempo mítico al protagonismo del presente

Más allá de esta propuesta se entiende que "una cosa es la negación de la cronología y otra el rechazo de cualquier principio sustitutivo de configuración” (Ricoeur, 1998b: 413), por eso es comprensible que gracias a las reglas de la ficción las expresiones narrativas míticas, cuentísticas o novelísticas se atengan a nuevos modos de organización temporal. Algunas de esas nuevas formas se constituyen por temporalidades (tiempo mítico) y configuraciones temporales (nunc stans y nunc fluens $^{7}$ que al centrarse en el presente constitu-

${ }^{7}$ Se verá tiempo mítico y nunc stans veladamente, resaltando ante todo sus diferencias con el nunc fluens. Este último concepto (el cual podría traducirse como "ahora fluyendo") fue introducido por el filósofo romano Boecio alrededor del 
yen artificios narrativos capaces de establecer un orden de sucesión por demás distinto.

Rozamos aquí un campo en el que se decidió no entrar desde el momento en que adoptamos como punto de partida la narración ficcional sin escindir, por un lado, la mítico-religiosa y por otro, la narrativa artística del cuento o la novela. $Y$ es que mientras la narrativa mítico-religiosa se centra en un tiempo sin paralelo Histórico (pues intenta explicar hechos o acontecimientos primigenios mediante dioses, heroísmos o maravillas sobrenaturales), la narración literaria y su consecuente tiempo del discurso ${ }^{8}$ puede inscribirse en una temporalidad real más o menos similar a la experiencia cotidiana de la realidad Histórica; en ella, dependiendo de los fines artísticos, en algún momento se escinde entre el tiempo cronológico -representación del tiempo lineal en relación con la instancia de la enunciación- y la temporalidad extraordinaria para fundar una experiencia estética fantástica, terrorífica, maravillosa o mágica.

La ruptura entre ambos tipos de narraciones ficcionales precede a este texto y también lo desborda, por tanto, en lugar de discernirlos con contundencia es pertinente ver la narración mítico-religiosa y literaria desde una comunión que a pesar de sus diferencias de forma y fondo permite situarlas fuera del tiempo Histórico.

Para matizar el inmenso caudal de información en este sentido, considerablemente más extenso de lo expuesto en estas páginas, se-

año 500 en su obra La consolación de la filosofía. En este texto aborda la noción de tiempo y eternidad. Como ya se dijo, también San Agustín refiere la idea del nunc fluens al menos tangencialmente. En el siglo XX, historiadores, filósofos y teóricos, como Ananda Coomaraswamy, Martín Toboso y Manuel Ballestero, fueron algunos de los estudiosos que recogieron el concepto.

8 "el tiempo del discurso es, en un cierto sentido, un tiempo lineal, en tanto que el tiempo de la historia es pluridimensional. En la historia varios acontecimientos pueden desarrollarse al mismo tiempo; pero el discurso debe obligatoriamente ponerlos uno tras otro" (Todorov, 2004: 180). 
guimos a Ricoeur y reservamos el término de ficción para aquellas historias que ignoran la pretensión de verdad inherente al relato Histórico, de ahí la vinculación mítica y literaria. Una vez aclarado esto, es momento de particularizar las licencias temporales que tienen cabida en la generalidad de la narrativa ficcional, pues como se explicó antes, si el sistema de ahistoricidad deviene de un discurso del arte o del mito no afecta a los objetivos trazados.

El tiempo mítico contraría la preconcepción lógica del tiempo, pues se trata de un periodo sagrado hecho presente no contaminado por el devenir, recuperable y repetible ad infinitum. "Podría decirse de él que no trascurre [...] Es un tiempo ontológico por excelencia: siempre igual a sí mismo, no cambia ni se agota" (Eliade, 1998: 54) pues expresa la plenitud de un presente sin historia. Para Eliade, se trata de una creencia religiosa universal que cree en la capacidad de volver a la edad mítica a través del mito y el rito. Como ya no es posible volver al periodo dorado del mito, los ritos religiosos y las festividades sacras funcionan para rememorar la edad primigenia del hombre y, aunque sea de modo artificial, expresar un lapso atemporal donde seres humanos y dioses coexisten en fraternidad compartiendo la tan anhelada inmortalidad divina. En pocas palabras, el tiempo mítico ${ }^{9}$ integra en su ahistoricismo a toda la atmósfera, ya sea litúrgica, filosófica o hasta sagrada dado que en su búsqueda de plasmar una realidad totaliter alter, manifiesta un gran tiempo hierático existente aparte del tiempo con duración normalizada. Lo anterior es comprensible al tomar en

${ }^{9}$ Como puede verse, el tiempo mítico tiene un origen diferente al del campo narrativo literario, no obstante, se devela en muchos relatos cuya pretensión es la de reconfigurar la temporalidad lineal. Por consiguiente, ha sido retomado en varios planteamientos teórico literarios y estéticos como los de Friedrich Nietzsche (su doctrina de die ewige Wiederkunft), James Joyce, Thomas Mann, Jorge Luis Borges, Gabriel García Márquez, y Alejo Carpentier, entre otros. 
cuenta que el hombre es capaz de sacralizar tanto el tiempo como el espacio cuando la circunstancia secular así lo requiere.

Diferente al tiempo mítico-pero en esencia análogo al ponderar el presente- es la configuración temporal del nunc stans, eternidad permanente sin cambio ni movimiento: "duración sin comienzo ni fin, o siendo ella en sí misma, como un punto inextenso de tiempo que es siempre ahora" (Toboso, 2003: 1). Si el tiempo mítico es un eterno retorno, circular, repetible y, por tanto, siempre igual a sí mismo; el nunc stans es presente en perpetua pausa "en el que todo permanece inmutable" (Coomaraswamy, 1999: 96). Como tal, temporalidad mítica y nunc stans funcionan en discursos narrativos donde se esquiva el fluir ordinario del tiempo para acentuar el eterno retorno y lo estable-estático, respectivamente. Ni el tiempo mítico ni el nunc stans entienden el tiempo en su totalidad o como una realidad en sí misma, por el contrario, lo conciben como una noción abstracta y construida desde la experiencia de ficción del tiempo, de un tiempo otro que choca con la práctica de la sucesión y continuidad del mundo tangible. De ahí su coincidencia en lo que podría llamarse un "aspecto temporal de una experiencia virtual del ser en el mundo propuesta por el texto" (Ricoeur, 1998b: 534).

A manera de preámbulo, se advierte que una de esas propuestas narrativas extraordinarias puede ser la de exponer un manar dinámico del presente que no permite el desenlace de los procesos desarrollados en ese periodo, es entonces cuando toca el turno de abocarnos al nunc fluens. 


\section{Las condiciones y la producción de sentido del presente eterno a través del nunc fluens}

Conviene no olvidar que el protagonismo del presente tiene una historia con amplios márgenes que superan la propia referencia del nunc fluens. De hecho, desde el siglo IV parecía advertir San Agustín la centralidad del ahora cuando sin nombrar de forma abierta esta configuración temporal, remarcó el presente: "No es propio decir, hay tres tiempos, pasado, presente y futuro. Pero tal vez se diría propiamente: Hay tres tiempos, el presente de las cosas, el presente de las presentes y el presente de las futuras" (2006: 334). Para el obispo de Hipona, el ahora es inextenso, ello a primera vista empareja su reflexión con el nunc fuens, el cual, de hecho tiene su origen en el seno de la filosofía como contraparte de la concepción historicista que establece ciertos códigos de realidad compartida. Como tal, entenderemos el nunc fuens como la alegoría de un mundo improbable y una realidad imposible.

El nunc fluens tiene su origen en el seno de la filosofía como una contraparte de la concepción Historicista, la cual establece ciertos códigos de realidad ${ }^{10}$ compartidos por la mayoría de los individuos. Como tal, entenderemos el nunc fluens como la alegoría de un mundo improbable y una realidad imposible. Ahora bien, no porque el nunc fluens exponga un presente en desarrollo vacía de significado al continuo de la duración del antes o después, como sí lo hace el nunc stans, el cual "comprende de forma simultánea toda la plenitud de la vida interminable" (Boecio, 1999: 183) pues para tener sentido no le hace falta futuro ni pasado. Aunque el nunc fluens privilegia el ahora, reconoce que para contar una histo-

${ }^{10}$ Entre ellos: biológicamente el individuo nace, vive y muere; sociológicamente el tiempo se experimenta como el fluir del pasado hacia el futuro; psicológicamente el devenir emprendido en el tiempo halla una conclusión, etcétera. 
ria debe comprenderse el presente del acontecimiento narrado en relación con:

el pasado inmediato de la historia, que es conservado por el acontecer que sucede en el presente, y en relación con el desarrollo futuro de la trama, que es anticipado [sólo anticipado pues en el nunc fluens el futuro no llega a concretarse] (Ricoeur, 1999: 146).

Hasta aquí podría cuestionarse esta primacía del presente tomando en consideración que éste posee un carácter escurridizo: "viendo que el presente no está fijo, ni siquiera por un instante, ¿cómo puede decirse que es presente? (literalmente que está) cuando no puede permanecer en equilibrio" (Coomoraswamy, 1999: 122). Sin embargo, el nunc fluens tiene la particularidad de terminar con la experiencia fugitiva del ahora al ser una "instantaneidad extensa en flujo, o un presente permanente que se prolonga y se mantiene como presente en devenir" (Ballestero, 1985: 102). De acuerdo con ello, este "Ahora que transcurre, como hacedor del tiempo" (Toboso, 2003: 21) bien puede consentir una condición presente donde los sujetos involucrados se mantienen en un proceso sin acabar, y es que si el ahora se desarrolla en extenso entonces se pospondría la llegada del futuro y, con ello, no habría fin para los procesos desplegados por el o los protagonistas de la narración ficcional.

La narración misma da la pauta para interpretar que hay una transición supeditada a la lógica de un ahora fluyendo cuando sus protagonistas ni retoman su condición previa a las transiciones ni acceden al término de éstas. El hecho de que el nunc fluens mantenga el presente no significa que niegue toda oportunidad de cambio o del despliegue de una historia, al contrario, al extenderse el ahora en el universo ficcional de las obras se propicia que los procesos de los sujetos representados continúen y la historia contada se centre en ese "llegar a ser". En resumen, el nunc fluens 
privilegia el presente sin hacerlo estático, es decir, no se trata de una pausa o detenimiento en los procesos contados, sino de una extensión perenne de ellos.

Por obvias razones este "llegar a ser" se despliega en el presente, pues por naturaleza "esquivar el presente es lo que no puede hacer el devenir (porque deviene ahora y no puede saltar por encima de este 'ahora')" (Platón apud en Deleuze, 2005: 199). Este devenir a veces se usa como sinónimo de "llegar a ser":

a veces se considera como el equivalente de 'ir siendo'; a veces se emplea para designar de un modo general el cambiar o el moverse" [Como se observa] Dentro de esta multiplicidad de significaciones parece haber, con todo, un núcleo significativo invariable en el vocablo 'devenir': es el que destaca el proceso del ser 0 , si se quiere, el ser como proceso" (Ferrater, 1999: 852; cursivas mías).

A todo esto podría preguntarse ¡esta clase de protagonista sobreviniendo sin intermisión puede existir en una temporalidad lineal, aunque ficcional? La respuesta es no; de ser así, el presente no se suspendería y el sujeto procesual no estaría siendo sino que pasaría por determinadas fases cronológicas hasta llegar a una etapa concluyente. Con su llegada en el universo ficcional de las narraciones ya no se trataría de un sujeto que deviene sino de uno que ha devenido y, por tanto, ha finalizado su transformación y ha alcanzado un nuevo estado, condición, carácter, existencia o apariencia.

En definitiva, "Acabar este devenir, es precisamente aquello de lo que [los sujetos en un nunc fluens] no son capaces, pues si lo acabaran, dejarían de devenir, serían" (Deleuze, 2005: 27). Al ser por completo otra cosa se rompería con la continuidad del ahora, por ende, en el nunc fluens los procesos siempre se superan o rebasan y nunca se sabe a ciencia cierta el estado definitivo de los protagonistas presentes en la narración, de ahí la incompatibilidad 
del nunc fluens en narraciones con desenlace terminante o sin cabos sueltos. Esto es básicamente lo que distingue a esta propuesta de una condición de ser sujeto en expresiones narrativas, de otras representaciones de transitividad en las cuales sí hay conclusión en el devenir.

Habrá que ser más cautelosos a este respecto, por eso reiteramos que aunque la narrativa no contiene el tiempo, sí lo representa, dado que "el mundo desplegado por toda obra narrativa es siempre un mundo temporal" (Ricoeur, 1998a: 39). En este sentido, conviene notar que si algo caracteriza a las expresiones narrativas es la doble estructura temporal: el orden cronológico de los acontecimientos, el cual conoceremos como una temporalidad global que envuelve la narración, y el orden de su presentación o temporalidad vital.

Seremos puntuales, temporalidad vital y global no son dos dimensiones sucesivas sino lecturas simultáneas del tiempo. Ambas coexisten en la narración ficticia pero una $u$ otra se privilegia porque al manejar los hilos del tiempo ficcional el autor siempre empleará la deformación temporal con ciertos fines estéticos. A veces busca crear la ilusión de realismo y de la imitación de un tiempo cronométrico racionalizando como el trascurrir, en cuyo caso, la temporalidad global gobierna la narración. $Y$ hay casos donde el fin estético es enfatizar la ficcionalidad y mostrar que la percepción del tiempo de los protagonistas es ajena a la cronología; por ende, se desarrollan mundos oníricos, subconscientes o fantásticos sin continuidad con lo Histórico. Sólo en esta temporalidad vital cabría hablar de configuraciones temporales como la que aquí nos ocupa.

El nunc fluens atenúa la llegada del futuro sólo en el mundo ficcional de la obra (asentado en la temporalidad vital). Sólo ahí el devenir queda establecido como carente de final posible ya que formalmente la expresión narrativa se desarrolla y prosigue hasta su 
cierre (ejemplificada con el punto final del relato). Ello demuestra que la idea de un devenir interminable dentro de un nunc fluens es sostenible sólo en términos teóricos como idea propia de la ficción.

Ahora bien, mientras en las narraciones ficticias 11 la temporalidad global es finita, 12 la temporalidad vital no siempre finaliza; ese es el caso de las expresiones narrativas donde se manifiesta el nunc fluens pues aunque la temporalidad global de la narración empieza y termina siendo lineal y respetando la cronología lógica de los eventos, la subjetividad con que el sujeto ficcional experimenta el tiempo puede apuntar al desarrollo sempiterno del "llegar a ser". En dicho mundo ficcional se pone en escena cómo el nunc fluens comprende el presente del acontecimiento recreado en relación con el pasado inmediato y con la anticipación del futuro, pero empeñándose en no verlos como ejes sino concentrándose en el devenir en pleno.

${ }^{11}$ Se trata de "un discurso representativo en el interior del cual deben distinguirse ante todo: el tiempo de la historia (o tiempo de la ficción, o tiempo narrado, o representado), temporalidad propia del universo evocado; el tiempo de la escritura (o de la narración, o relatante) tiempo ligado al proceso de enunciación, igualmente presente en el interior del texto, y el tiempo de la lectura (mucho menos evidente), representación del tiempo necesario para que el texto leído" (Ducrot, 1974: 359).

${ }^{12} \mathrm{La}$ narrativa de ficción está cerrada en su estructura. No puede añadirse o incorporarse ningún elemento, aunque claro, en esencia, la historia está abierta para la participación activa del receptor, quien puede reactualizarla con regularidad. Resaltar este punto era importante para evitar malentendidos pero abundar en esta cuestión es inoperante en este trabajo que no tiene como tarea específica analizar la relación obra-recepción. 


\section{El colofón: las posibilidades y limitaciones del nunc fuens}

A propósito de la potencialidad del nunc fluens, no podríamos obviar la reflexión de Heidegger, quien aun sin mencionar un tiempo sin tiempo abona a la pretensión de ahistoricidad advirtiendo que, aunque existe un marco Historicista, éste no es capaz de explicar el curso de la existencia misma a nivel ontológico; para ello es necesario hablar de una temporalidad no Histórica que al surgir directamente del Dasein no admite escindir entre conceptos ficticios a la luz del todo, como el antes y el después (Heidegger, 2005). En sentido análogo, Octavio Paz advertía: "apenas el tiempo se divide en ayer, hoy y mańana, en horas, minutos y segundos, el hombre deja de ser uno con el tiempo, cesa de coincidir con el fluir de la realidad" (1999: 226), o en otras palabras, pierde validez ontológica. Con todo, el nunc fluens se convierte en una alternativa para escapar de la típica prisión unidireccional y a la vez, dirigirse hacia otra circunstancia donde cabe hablar de la permanencia de un ahora que se fluidifica interminablemente.

Conforme a su peso específico (ya sea en la narrativa Histórica o ficticia), el tiempo es axial para entender cómo las cosas cambian y los actos pasan; no obstante, la problemática se acrecienta cuando, a la manera del nunc fluens, no hay lugar para el transcurrir de un estadio a otro. Esta concepción de sentido inédita en la narrativa ficcional apuntala la propuesta de un tiempo poético que permitiría ver con nuevos lentes a historias pobladas por protagonistas con una determinada forma de ser "siendo". De acuerdo con ello, inquirir en la representación temporal de expresiones narrativas de ficción no es del todo novedoso pero sí muy fértil, más aún si se piensa cómo a través de dichas manifestaciones el tiempo se hace más subjetivo y menos real (en el sentido cronológico o fisiológi- 
co). Innumerables planteamientos han tenido como eje este aspecto y el presente texto no era la excepción.

Aunque el individuo en la vida real puede captar un periodo, como un lapso más o menos corto según su subjetividad, e incluso puede tener la sensación momentánea de que el tiempo se suspende en un presente que no pasa, esta sensación se desvanece rápido al reparar en que antropológicamente el reloj avanza y las actividades se suceden, terminan y comienzan otras, ya que "En la vida actual no se vive más que el presente fugaz y transitorio" (Boecio, 1999: 183). Aunque no es posible para un ahora seguir siendo siempre el mismo, la configuración temporal del nunc fluens abona en la noción de vivir el presente, abstracción en la que las cualidades de esta idea (la sensación imaginaria de que el ahora de extiende) se consideran en su pura esencia; por tanto, sólo se concretizan en manifestaciones narrativas ficcionales mítico-religiosas o literarias ${ }^{13}$.

En virtud de lo anterior, considerar sustancialmente el presente no está exento de problemáticas, empezando por el hecho de que exponer un final postergado podría frustrar o trastocar las expectativas del receptor de la narración literaria o mítico-religiosa. Y es que aunque estos discursos sean per se capaces de cuestionar el uso de la temporalidad como ordenación sistemática de los incidentes de la vida, el solo hecho de pensar en una transición sin fin resulta incierto, dado que en esencia, "vincular un comienzo con un fin [es] ofrecer a la imaginación el triunfo de la concordancia sobre la discordancia” (Kermode, 1998: 409).

Sobre este punto, Kermode advirtió la importancia de estudiar el tiempo narrativo desde su conclusión. Centrado en el discurso

${ }^{13}$ No obstante el foco de atención de este texto, no deberíamos prescindir de estudiar el nunc fluens en narraciones visuales donde también puede percibirse esta determinada manera de vivir el tiempo, para muestra: el cine o la pintura narrativa. 
trágico, para Kermode una manera de dotar de significado al tiempo era justamente mediante una clase de "anticierre" que atentaba contra la perspectiva tradicional de la literatura del siglo XIX en la que, "el final de la obra tiende a confundirse con el de la acción representada; entonces tiende a simular el cese de actividad del sistema de interacciones que forma la trama de la historia narrada" (Ricoeur, 1998: 407). Kermode resolvió que dentro de la tragedia Shakesperiana existe un tiempo de crisis que simula un final inconcluso en el que los horrores y el caos precedidos, imposibilitaban siquiera pensar en una vuelta al orden cronológico: "más allá de lo peor aún hay algo peor, y el propio final no es más que una imagen del horror de la 'crisis'; King Lear es la tragedia de lo sempiterno en el orden del infortunio" (Kermode apud en Ricoeur, 1998: 410; cursivas mías). Así las cosas, ante la magnitud del horror, restaurar la linealidad deuna extensión temporal con principio y fin, resultaría a todas luces falsa.

Entendemos el análisis de Kermode sobre el "tiempo de crisis" como el simulacro del eterno presente (nunc fluens) en donde un final continuamente aplazado puede servirle en la intención narrativa para resaltar que hay temáticas sin intermisión. Si el nunc fluens con su consecuente inconclusión narrativa funciona para poner de relieve lo irresoluble, y lo irresoluble para el ser humano suele ser lo relativo a emociones de desasosiego, entonces podemos apuntar que uno de los mayores alcances y, paradójicamente, de las condiciones limitantes más claras del nunc fluens es precisamente su vínculo con la representación de un presente trágico, puesto que la realidad trágica se vuelve contra la propia idea de composición ordenada.

Si esto es así es porque al plantear el nunc fluens la narración ficticia carece de un acontecmiento nuevo que rompa con el presente e inicie algo diferente para los protagonistas del relato; sin un espacio de experiencia (pasado) o cualquier tipo de horizonte 
de espera (futuro), es natural pensar que el protagonista subsiste en medio de una prolongada espera que, siguiendo a Kermode, podría terminar en una extensión perenne del no movimiento (ya lo señalaba Aristóteles) y, por ende, de la exclusión del cambio indispensable en la evolución de toda existencia. Los discursos narrativos ficcionales en los que tendría presencia el nunc fuens expondrían entonces personajes que padecen un limbo fácilmente emparejado a la agonía o al tormento sin fin, pues sufrir es, en su naturaleza, estar detenido en el dolor.

Postulamos que el nunc fluens es una configuración que en la narrativa ficcional literaria o mítico-religiosa está ligada a la experiencia o la praxis del sufrimiento con terminación no conclusiva; en él, no habría descansos o escapatorias hacia mundos más satisfactorios, en otras palabras, evocar el nunc fluens resultaría prácticamente en referir el mismísimo infierno.

A lo largo de esta exposición se cimentó una propuesta con un cariz denso que pese a no buscar transitar indiferentemente por las fronteras de una u otra disciplina, en ocasiones fue sobrepasada por el tono resbaladizo de la temática alrededor del tiempo. El paso de una tesis a otra encuentra una justificación parcial en el hecho de que en la propia idea del tiempo nos viene dada su complejidad. Si bien el marco de referencias resulta estrecho, ello no hace más que destacar el potencial interdisciplinario del presente acercamiento teórico, el cual nunca ha pretendido mostrar todos los matices de análisis acerca del tiempo. Justo por ello reconocemos que las posibilidades teóricas alrededor del nunc fluens son enormes y pueden derivar en otros estudios que indaguen en los aspectos que por cuestiones de tiempo y alcances específicos no fueron abordados, por ejemplo: el papel del nunc fluens dentro de la literatura fantástica e incluso consideraciones ontológicas que refieran esta configuración temporal en relación con la condición de un ser/no-ser/siendo; cada una de estas líneas merecerían un rol 
protagónico que ameritarían sendos trabajos de análisis inalcanzables bajo el esbozo general planteado en el presente texto.

Por último, resaltamos que el propio devenir del proyecto parece cerrar el círculo con el que inició su reflexión. Y es que quizá como consecuencia natural de la dificultad de eludir la sentenciosa y alegórica línea del tiempo, al final de esta dilucidación se entrevé una circularidad tautológica: si el tiempo es medida y por tanto, es inherente a él la caducidad o el paso de los periodos, entonces el nunc fluens no termina por ser un tiempo ¿o es un tiempo sin tiempo? Lejos de resolver una interrogante tal, se reitera que en estas páginas no se buscó considerar a la temporalidad en su condición abstracta de absoluto indescifrable, únicamente se trabajó el concepto a la luz de una temporalidad relativa, que al tomar carácter en determinados discursos de ficción, posibilita la interpretación de un tiempo poético.

Este análisis del tiempo narrativo termina así en el entendido de un universo ficcional en donde existe un sucederse que no termina (pues no categoriza una parte del continuo de la duración pasada y futura) y, de paso, constituye una respuesta al carácter aporético de la especulación sobre el tiempo.

\section{Bibliografía}

Acosta Escareño, Javier, 2007, Schopenhauer, Nietzsche, Borges y el eterno retorno, Madrid, Universidad Complutense de Madrid.

Agustín de Hipona, 2006, Confesiones, Gustavo Piemonte (trad.), Argentina, Ediciones Colihue.

Aristóteles, 1998, Física, Biblioteca Clásica, Madrid, Gredos.

Ballestero, Manuel, 1985, El devenir y la apariencia, España, Anthropos. 
Barthes, Roland, 2004, La cámara lúcida. Nota sobre la fotografia, Joaquín Sala-Sanahuja (trad.), México, Paidós.

Boecio, 1999, La consolación de la filosofía, España, Alianza.

Campillo, Antonio, 1991, “Aión, Chrónos, Kairós, la concepción del tiempo en la Grecia Clásica", en Las otra(s) historia(s). Una reflexión sobre los métodos y los temas de la investigación histórica, núm. 3, España, UNED/Bergara, pp. 33-70.

Chatman, Seymour, 1980, "What Novels Can Do That Films Can't (And Vice Versa)" Critical Inquiry, vol. 7, núm. 1, The University of Chicago Press Stable, pp. 121-140. Disponible en: http://www.jstor.org/stable/1343179 (consultado el 25/ $\mathrm{VIII} / 2014)$

Coomaraswamy, Ananda, 1999, El tiempo y la eternidad, Pedro Rodea (trad.), Barcelona, Kairós.

Croce, Benedetto, 2005, La historia como hazaña de la libertad, Argentina, FCE.

Deleuze, Gilles, 2005, Lógica del sentido, Miguel Morey (trad. y prólogo), España, Paidós.

Ducrot, Oswald y Tzvetan Todorov, 2006, Diccionario enciclopédico de las ciencias del lenguaje, Enriqueta Pezzoni (trad.), México, Siglo XXI.

Eliade, Mircea, 1998, Lo sagrado y lo profano, Luis Gil (trad.), España, Paidós.

,2001, El mito del eterno retorno, Argentina, Emecé.

Elias, Norbert, 2010, Sobre el tiempo, Guillermo Hirata (trad.), México, FCE.

Ferrater Mora, José, 1999, Diccionario de filosofía, Josep-María Terricabres (ed.), España, Ariel.

Heidegger, Martin, 2005, El ser y el tiempo, José Gaos (trad.), España, FCE. 
Jaques, Elliot, 1984, La forma del tiempo, José Luis Etcheverri (trad.), Argentina, Paidós.

Kant, Emanuel, 1988, Crítica de la razón pura, Madrid, Alfaguara.

Mondolfo, Rodolfo, 2004, Heráclito, textos y problemas en su interpretación, Oberdan Caletti (trad.), México, Siglo XXI.

Paz, Octavio, 1999, "Apéndice. La dialéctica de la soledad”, en $E l$ laberinto de la soledad, México, FCE.

Platón, Timeo, 1982, Madrid, Gredos.

Ricoeur, Paul, 1998a, Tiempo y narración I. Configuración del tiempo en el relato histórico, México, Siglo XXI.

, 1998b, Tiempo y narración II. Configuración del tiempo en el relato de ficción, México, Siglo XXI. Siglo XXI.

, 1998c, Tiempo y narración III. El tiempo narrado, México, , 1999, Historia y narratividad, España, Paidós.

Toboso Martín, Mario, 2003, “Tiempo y sujeto V. Análisis del espectro en la experiencia temporal", A parte rei: Revista de flosofía, núm. 31, pp. 1-29. Disponible http://serbal.pntic.mec. es/ c cmunoz11/toboso31.pdf (consultado el 11/IX/2010).

Todorov, Tzvetan, 2004, "Las categorías del relato literario", en Roland Barthes et al., Análisis estructural del relato, México, Ediciones Coyoacán, pp.161-197.

Recibido: 20 de julio de 2015 Aceptado: 14 de diciembre 2015 